\title{
A NEW WAY TO LOOK AT THE PRAIRIES
}

ALEX ZELLERMEYER, Prairie Wildlife Interpretation Centre, P.O. Box 10, Webb, Saskatchewan, SON 2XO.

Each year at the height of the summer, over 20,000 people a day pass through the Swift Current area on the Trans Canada Highway. For almost $30 \%$ of these people, the prairie section of the cross country route is their only lifetime experience with the grasslands. Not suprisingly, most people find it a bore - an extended $70 \mathrm{mph}$ sprint through a desolate windswept barrens - a lifeless monotony of wheatfields and pastures between Winnipeg and Banff. Or so it seems. These misconceptions are well known. This article deals with a project to do something about them.

In the mid-1960's the Canadian Wildlife Service recognized the detriment to Canada's wildlife habitats caused by a general lack of environmental awareness. Through an Interpretation Section, the Service initiated a series of programs called 'Trans Canada Houses' in each of the country's major natural regions which would allow the travelling public to experience and learn about the different parts of the Canadian natural history mosaic.

In 1969 the first program was opened at Midland, Ontario: the Wye Marsh Wildlife Centre which deals with the hardwood country of eastern Canada. Since that time, three other Centres have come into operation. The Perce Wildlife Centre at Perce, Quebec, tells the story of the Atlantic coast, and the Creston Valley Wildlife Centre deals with the mountain habitats of British Columbia. The fourth and newest program in the series is perhaps the most challenging - the Prairie Wildlife Interpretation Centre - a program to bring the prairies alive for a public that has generally stereotyped this landscape as 'flat and barren'.

What is the Wildlife Interpretation Centre? It is an opportunity for the public to experience the elements of the prairies first-hand, not from a speeding automobile or the sweltering cement of a gas station stop, but along a prairie trail: coulees, cattail sloughs, yellowheaded blackbird colonies, alkali lakeshores, ground squirrels, shorebirds, waterfowl, wheatfields. These are some of the elements of today's prairie. The key word is today. Canadian Wildlife Service programs do not have a preservation basis. That mandate belongs federally to Parks Canada. The Prairie program tells the story of the plains as they are today, the factors that have influenced, shaped, and altered the wildlife and wildlife habitats of the region.

This contemporary approach to prairie interpretation has direct effects on the Centre's management and program presentation. For instance, the 1,100 acres of Wildlife Centre property is basically a 'manhandled' piece of land. Cultivation and grazing have been traditional activities and will continue to be so on selected portions of the property. Activities such as these have been major agents of change 


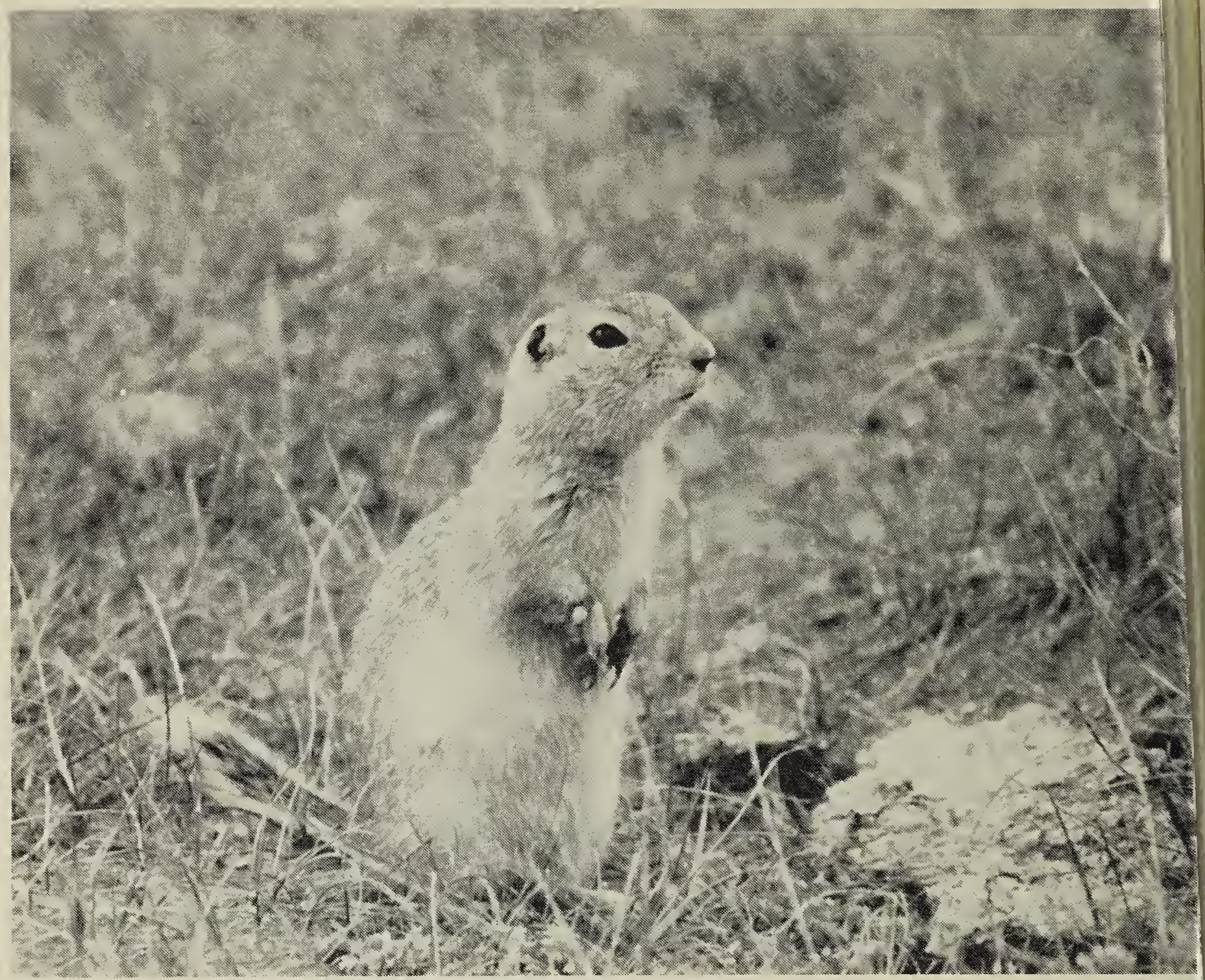

Richardson's Ground Squirrel

G. W. Beyersbergen

on the prairie landscape, and it is these changes that are presented to the public. It is also this environment that the public sees on their passage through the prairies, and which the Canadian Wildlife Service feels must be better understood to prevent mismanagement in the future so that wildlife may survive in spite of our intensive land use practices. Here is a reality that Canadians are learning to understand. It is not enough to simply preserve certain pristine sections of our environments as examples of what once was. That is important, but not enough by itself. Such preservation can foster the mistaken belief that all is well if we set aside examples of untouched habitats. We must also learn to manage the rest of our landscapes with an eye to intelligent land stewardship where the rest of our biological world has consideration. The Prairie Wildlife Interpretation Centre, and the Canadian Wildife Service Interpretation program are tools to bring about that farsighted goal. The short-term benefit is simply that the travelling public will get a look at the prairies they never expected. They will get a chance to stretch their legs and learn things that will make this continued prairie drive more alive, and more meaningful.

The Centre also offers an opportunity for the accomplished naturalist to see a cross-section of the short grass plains natural and cultural history on a compact and accessible piece of land. Although inventories are far from complete, the Centre has a hypothetical list of 43 mammals (15 have been observed on the land). 
